\title{
Instruções sobre as escolas de primeiras letras expedidas pelo Príncipe Regente e o Conde de Linhares (Porfugal, 1798-1800)
}

\section{Instructions on the first lessons schools issued by the Prince Regent and the Count of Linhares (Portugal, 1798-1800)}

\section{Instrucciones sobre las escuelas de primeras lecciones emitidas por el Príncipe Regente y el Conde de Linhares (Portugal, 1798-1800)}

Nos anos de 1798, 1799 e 1800, foram expedidas instruções sobre as escolas de primeiras letras pelo Príncipe Regente D. João VI e pelo Conde de Linhares, D. Rodrigo de Souza Coutinho endereçadas aos Bispos e Governadores do Rio de Janeiro e Pernambuco, com cópias para as autoridades das principais capitanias do Brasil, na forma de Cartas Régias, principalmente. Esses documentos (em número de 8) dizem do esforço da Corte do Príncipe Regente e de seu principal Secretário, Conde de Linhares, pela valorização da educação pública do Brasil no fim do século XVIII. O primeiro Conde de Linhares, D. Rodrigo de Souza, "homem das luzes" favorecido pelo Marquês de Pombal, assumiu os cargos ministeriais de Lisboa na corte do Príncipe Regente D. João VI em 1796. Num contexto adverso do retorno ao ensino coordenado pelos religiosos por decisão da Rainha D. Maria, D. Rodrigo de Souza incentivou o Príncipe Regente a expedir ordens com fins de laicizar a educação, não obstante, a condução de Religiosos da Companhia de Jesus para valorizar os professores por seu esforço, dedicação e práticas de ensino, tidas como inovadoras.

\section{Documento 01}

\section{Carta Régia para o Bispo de Pernambuco}

Reverendo Bispo de Pernambuco do Meu Conselho. Eu a Rainha vos envio muito saudar. Sendo-me presente o Requerimento em que Me pedis que para o estabelecimento de um Seminário na vossa Diocese para a educação da mocidade Eu fosse Servido mandar pagar pelo Cofre do Subsídio Literário 
aos Professores que para ele fossem nomeados, e ordenar que cada pessoa de toda aquela Diocese de doze anos para cima contribuísse com dez ou vinte reis anualmente para o sustento dos Estudantes e Seminaristas pobres e das Pessoas da Regência e Serviço do mesmo Seminário. Esperando eu que deste estabelecimento resultem muitas utilidade assim a vossa lgreja como a toda a Capitania de Pernambuco sendo por outra parte necessárioque com a nova criação do Seminário se não aumente por ora a Despesa que atualmente se faz com os Professores e Mestres da mesma Capitania e que da mesma sorte os atuais professores não fiquem privados dos Ordenados que percebem. Querendo autorizar-vos para que possam melhor dispor tudo o que for necessário para o referido estabelecimento: Hei por bem nomear-vos Diretor Geral dos Estudos daquela Capitania e ordenar que se vos entregue aos Quarteis toda a importância da Folha dos Ordenados que ao presente se pagam aos Professores e aos Mestres da referida Capitania encarregando-vos o pagamento dos mesmos, e autorizando-vos a que possam transferir para o Seminário algumas das Cadeiras que se acham atualmente no Recife e em Olinda, se esta translação se poder fazer sem grave inconveniente, como também que a medida que forem vagando algumas Cadeiras Me possam consultar as que se poderão 2 suprimir a beneficio do Seminário sem prejuízo da Instrução Pública e para que estas Disposições e as mais que forem precisar para a criação do Seminário se possa fazer com inteiro e individual conhecimento dos meios mais próprios para o acerto; vos Ordeno que no Comboio que deve partir no Mês de Julho próximo, vós transportei sem mais demora à vossa Diocese, o que ali deis principio ao que for praticável fazer-se para o Estabelecimento do Seminário na certeza de que com a vossa presença adiantar-se muito esta importante obra e conhecereis melhor quais são os obstáculos que se devem remover e os meios que se devem aplicar para que ela se estabeleça com solidada e aperfeiçoada e por este modo Me informarei plenamente do que precisar de novas Providencias Minhas para que se vos disse todas as que forem mais próprias ao referido objeto. Quando a contribuição pessoal, de que vós bem trateis ao Governador e Capitão General da Capitania, ordeno que ouça sobre este ponto as Câmaras que convido elas voluntariamente; e não de outro modo, se possa estabelecer a dita contribuição de cuja a cobrança se deveram encarregar os Párocos, afim de evitar as Despesas de Arrecadação e estas sem mais vos serão entregues para que as apliqueis ao fim a que se destinam. Escrito no Palácio de Queluz em 13 de abril de 1798. Príncipe Regente. 


\section{Referências}

DOM JOÃO VI. Príncipe Regente de Portugal. Ordens expedidas para o Brasil sobre as escolas das primeiras letras. Queluz, 1798. Documentos Manuscritos. (Notação Doc. 01 . Cat. Linhares n 313. Coleção Linhares da Biblioteca Nacional do Rio de Janeiro, Seção Manuscritos). Disponível em: http://objdigital.bn.br/objdigital2/acervo_digital/ div_manuscritos/mss 1457978/mss 1457978.pdf. Acesso em: 3 jun. 2019.

\section{Documento 02}

\section{Carta Régia para o Conde de Rezende}

Conde de Rezende, Dom José de Castro, Vice-Rei, e Capitão General de Mar e Terra do Estado do Brasil, Amigo. Eu o Príncipe vos Envio muito saudar como aquele que estimo. Sendo-lhe presente o triste e deplorável estado em que se acham as Escolas Menores em todas as Capitanias do Brasil pela falta de sistema com que se acham estabelecidas as Cadeiras necessárias para a Instrução Publica, pela qualidade das mesmas em que pouco se atendeu ao que mais era necessário no Local onde se estabeleciam as sobreditas Cadeiras pela falta de uma norma fixa e arrazoada para a nomeação e escolha dos mesmos Professores, e para a permanente instrução sobre o cuidado, atividade e zelo com que os Professores cumpram as suas obrigações e finalmente pela falta de proporção entre as Cadeiras que se estabeleceram e as Rendas e produtos do Subsídio Literário, que deve servir ao pagamentos dos seus honorários. Hei por bem ordenar-vos que proceda ao exame de todos esses objetos e que miúda e circunstanciadamente Me informeis. Primeiro, sobre o quantitativo atual e sobre o aumento que poderá ter o Subsídio Literário quando bem administrado ou arrendado em pequenas porções para o que vos Dou toda e necessária autoridade, a fim que possas desde logo fazer que este Ramo de Renda Pública se eleve ao maior auge que se possa. Segundo, sobre o número e qualidade de Cadeiras que será necessário conservar e das que convirá suprimir, tendo também em consideração que na Capital dessa Capitania determine que se estabeleça uma Cadeira de Aritmética, Geometria e Trigonometria, onde possam tornar-se e educar-se bons Contadores e Medidores, afim de que se não tinha a falta que há de bons contadores, e que as medidas das sesmarias se façam com a necessária exatidão, além da utilidade que há de haver Geômetras, Topógrafos capazes de levantarem Planos 
e até de darem convenientes Disposições dos Territórios e dos Rios, com a nota dos trabalhos que nos mesmos podem empreender-se. Terceiro, que desde já fiqueis na inteligência que a vós e ao Bispo pertence nomear os Professores para as Cadeias que vagarem, e que vos Encarrego de Me propor a forma e modo com que poderão estabelecer-se os Exames para os Candidatos ás Cadeiras que vagarem e, que no caso que concordeis com o Bispo sobre a escolha, deveis ambos fazer subir á Minha Real Presença a Proposta com as razões que tendes para adotar diferentes opiniões, afim que Eu decida e Escolha a que me parecer mais fundada. Quarto, que a vós unicamente como Governador pertence a Suprema Inspeção sobre as Escolas, exceto no caso que por particulares motivos dispense nesse princípio e encarregue algum Bispo essa especial Comissão, e aquele Governador ou Bispo a quem eu confiar esse particular encargo, the dou todo o poder para censurar e castigar e vigiar sobre a conduta e exação de serviço e procedimento dos mesmos Professores, informando dos que necessitarem maiores castigos e a total perda da sua Cadeira, ficando só autorizado para os suspender do exercício enquanto se Me dá parte, e o Professor se justifica, ou se deixa conhecer a justiça do procedimento que com ele se praticou. Deste modo confio que aplicando todas 4 as vossas luzes e esforços ao exame de tão importante matéria fixarei um Plano que seja merecedor da Minha Real Aprovação, e de que se siga a melhor Instrução dos Meus Vassalos nessa Capitania. Recomendando-vos tão bem que não vos esqueça o segurar e o animar o estudo das Línguas Latina e Grega para que na Escola daqueles incomparáveis Mestres se forme o gosto da Mocidade instruída, e que assegurando-se aos Professores o exato pagamento dos seus Honorários se aplique também algum fundo para a Jubilação dos Mestres que depois de longos anos de serviço se impossibilitarem e para premiar com algumas Medalhas de valor os Discípulos ou Alunos das mesmas Escolas que anualmente fizerem alguma composição de distinto merecimento ou publicarem alguma obra que mereça passar a posteridade. $\bigcirc$ que tudo vos Hei por muito recomendado. Escrita no Palácio de Queluz, aos 19 de agosto de 1799. Príncipe Regente.

Nesta mesma conformidade e data se escreveram para os Governadores das Capitanias da Bahia, Minas Gerais, São Paulo, Pernambuco, Pará, Maranhão, Goyazes, Matto Grosso, Itha dos Açores, Índia, Angola, Moçambique a llha da Madeira. 


\section{Referências}

DOM JOÃO VI. Príncipe Regente de Portugal. Ordens expedidas para o Brasil sobre as escolas das primeiras letras. Queluz, 1799. (Documentos Manuscritos. Notação Doc. 01. Cat. Linhares n 313. Coleção Linhares da Biblioteca Nacional do Rio de Janeiro, Seção Manuscritos). Disponível em: http://objdigital.bn.br/objdigital2/acervo_digital/ div_manuscritos/mss 1457978/mss 1457978.pdf. Acesso em: 3 jun. 2019.

\section{Documento 03}

\section{Instruções de D. Rodrigo de Souza Coutinho para o Conde de Rezende}

Ilustríssimo e Excelentíssimo Senhor.

Havendo o Príncipe Regente Nosso Senhor cometido a Vossa Excelência pela sua Carta Régia de 19 de agosto do presente ano em benefício da Instrução Pública geral de todos os Povos, seus fiéis Vassalos residentes nessa Capitania, a privativa e necessária Inspeção de todas as Escolas Régias que nela se acham estabelecidas e que de novo devem estabelecer para se educar e instruir a Mocidade nos conhecimentos das Línguas Gregas e Latina, da Retórica, da Filosofia, e da Aritmética, Geometria e Trigonometria, cujas as cadeiras de novo mando criar e estabelecer para os utilíssimos fins substanciados na sobredita Carta Régia. E desejando o mesmo Augusto Senhor fazer patente a seus fieis Vassalos o zelo e interesse que tem em promover a Instrução Pública e a facilidade geral dos seus Povos, é servido ampliar as Reais Decisões que aos sobreditos respeito na mesma se acham contidas ordenando para o exato regime de todas as Escolas que os Governadores a quem tem encarregado desta tão importante Comissão nomeiem em cada ano Letivo um Lente ou Professor que pela sua literatura, atividade e zelo do seu Real Serviço do bem Público, e igualmente pelo seu virtuoso e exemplar comportamento se façaa credor de uma maior confiança para que vá fazer a rigorosa visita das Escolas, examinando a assiduidade e diligência dos Professores e Mestres no cumprimento de tão essenciais deveres, do Método que seguem nas Lições e Explicações dos Autores, da escolha dos Livros por onde ensinam; da forma, tempo e horas com que regulam a Ordem e Disciplina das Escolas, do aproveitamento das Discípulos que as frequentam, vigiando mui severamente a sua morigeração e do resultado destas visitas que se deveram fazer sempre em 
tempo e horas incertas para que os Professores e Discípulos se conservem cuidadosos nos Exercícios Escolásticos, deverá Vossa Excelência remeter anualmente ou em cada seis meses a esta Secretaria de Estado dos Negócios das Marinhas e Domínios Ultramarinos para subir a Real Presença do Príncipe Nosso Senhor uma conta exata que deverá vir acompanhada, além das Listas dos Discípulos e Alunos das observações que ocorrem ao Lente Visitador com as informações que Vossa Excelência julgar oportunas, tanto para o melhoramento e adiantamento das mesmas Escolas como para se conservarem naquele pé respeitável de Ensino, e de Instruçãoem que Sua Alteza Real muito deseja que elas se conservem. Deus Guarde Vossa Excelência. Palácio de Queluz em 3 de setembro de 1799. D. Rodrigo de Souza Coutinho.

Nesta mesma conformidade e data escreveram aos governadores da Capitania da Bahia, São Paulo, Minas Gerais, Goias, Pará, Maranhão, Angola, Moçambique, Índia, Itha da Madeira, Ilha dos Açores, Mato Grosso e Pernambuco.

\section{Referências}

COUTINHO, D. Rodrigo de Souza. Ordens expedidas para o Brasil sobre as escolas das primeiras letras. Queluz, 1799. (Documentos Manuscritos. Notação Doc. O 1. Cat. Linhares n’ 313 . Coleção Linhares da Biblioteca Nacional do Rio de Janeiro, Seção Manuscritos). Disponível em: http://objdigital.bn.br/objdigital2/acervo_digital/div_manuscritos/ mss 1457978/mss 1457978.pdf. Acesso em: 3 jun. 2019.

\section{Documento 04}

\section{Instruções de D. Rodrigo de Souza Coutinho para o Bispo de Pernambuco}

Excelentíssimo e Reverendíssimo Senhor.

Havendo o Príncipe Regente Nosso Senhor nomeado Vossa Excelência pela sua Carta Régia de 13 de abril do ano próximo passado de 1798 Diretor Geral dos Estudos dessa Capitania Geral de Pernambuco; e havendo igualmente cometido a Vossa Excelência em benefício da Instrução Pública e geral de todos os Povos seus fiéis Vassalos residente nessa mesma Capitania a 
privativa e necessária Inspeção de todas as Escolas Régias que nela se acham estabelecidas, e que de novo se devem estabelecer para se educar e instruir a Mocidade nos conhecimentos das Línguas Gregas e Latina, da Retórica, da Filosofia, e da Aritmética, Geometria e Trigonometria, cujas as cadeiras de novo mandou criar e estabelecer pela outra Carta Régia de 19 de agosto para os utilíssimos fins na mesma substanciados. E desejando o mesmo Augusto Senhor fazer patente a seus fiéis Vassalos o zelo e interesse que tem em promover a Instrução Pública e a felicidade geral dos seus Povos, é ser vido ampliar as suas Reais Decisões que aos sobreditos respeito na mesma se acham conteúdas, Ordenando para o exato regimento de todas as Escolas que os Governadores e que tem encarregado desta tão importante comissão, nomeiem a cada ano Letivo um Lente ouProfessor que pela sua Literatura, atividade e zelo do seu Real Serviço e do bem Público e igualmente pelo seu virtuoso comportamento se faça credor de uma maior confiança para que vá fazer a Rigorosa Visita das Escolas, Examinando a assiduidade e diligência dos Professores e Mestres no cumprimento de tão essenciais deveres do método que seguem nas lições e explicações dos Autores da escolha dos Livros por onde ensinam da forma, tempo e horas com que regulam a ordem e disciplina das Escolas; do aproveitamento dos Discípulos que as frequentam, vigiando mui severamente a sua morigeração e de resultado destas Visitas que se deveram fazer sempre em tempos e horas incertas para que os Professores e Discípulos se conservem cuidadosos nos exercícios Escolásticos deverá Vossa Excelência remeter anualmente ou em cada seis meses a esta Secretaria de Estado dos Negócios da Marinha e Domínios Ultramarinos para subir a Real Presença do Príncipe Nosso Senhor uma conta exata que deverá vir acompanhada além das Listas dos Discípulos e Alunos, das observações que ocorrem ao Lente Visitador com as Informações que Vossa Excelência julgar oportunas, tanto para o melhoramento e adiantamento das mesmas Escolas, como para se conservarem naquele pé respeitável de ensino e de Instrução em que Sua Alteza Real muito deseja que elas se conservem. Deus Guarde a Vossa Excelência, Palácio de Queluz, em 3 de setembro de 1799. D. Rodrigo de Souza Coutinho. 


\section{Referências}

COUTINHO, D. Rodrigo de Souza. Ordens expedidas para o Brasil sobre as escolas das primeiras letras. Queluz, 1799. Documentos Manuscritos. Notação Doc. 01 . Cat. Linhares no 313. Coleção Linhares da Biblioteca Nacional do Rio de Janeiro, Seção Manuscritos). Disponível em: hitp://objdigital.bn.br/objdigital2/acervo_digital/div_manuscritos/ mss 1457978/mss 1457978.pdf. Acesso em: 3 jun. 2019.

\section{Documento 05}

\section{Carta Régia para o Reverendo Bispo de Pernambuco}

Reverendo Bispo do Rio de Janeiro, Amigo. Eu, o Príncipe Regente vos Envio muito saudar. Sendo-the presente o triste e deplorável estado a que estão reduzidas as Escolas menores em todas as Capitanias do Brasil, pelo falta de Sistema com que se acham estabelecidas nas cadeiras necessárias para a Instrução Pública, pelas qualidades das mesmas, em que pouco se atendeu ao que mais era necessário no local onde estabeleciam as sobreditas Cadeiras, pela falta de uma norma fixa e arrazoada para a nomeação e escolha dos Professores e para a permanente inspeção sobre o cuidado, atividade e zelo com que eles cumprem as suas obrigações, e finalmente pela falta de proporção entre as cadeiras que se estabeleceram e as Rendas e Produto do Subsídio Literário que devem servir ao pagamento dos seus Honorários. Fui servido ordenar ao Vice Rei e Capitão General de Mar e Guerra do Estado do Brasil e a os mais Governadores e Capitães Generais do mesmo Estado, que cada um na sua respectiva Capitania procedesse ao exame de todos aqueles objetos, e que miúda e circunstanciadamente Me informasse sobre o quantitativo atual e sobre o aumento que poderá ter o Subsídio Literário quando bem administrado ou arrendado em pequenas porções para o que the Concedi toda a necessária autoridade e sobre o número e qualidade de Cadeiras que será necessário conservar ou suprimir. E pelo que toca a nomeação dos Professores para as Cadeiras que vagarem, Determinei que os respectivos Governadores e Capitães Generais juntamente com os Bispos ficassem pertencendo as sobreditas nomeações; e no caso que os Bispos não concordassem com os Governadores sobre a escolha dos sujeitos que deviam ser nomeados, um e outro, fariam subir a Minha Real Presença a proposta com as razões em que se fundasse a diferença das opiniões; afim de que eu Decidisse e 
Escolhesse o que mais bem fundada the parecesse e ao mesmo Vice-Rei e ao mais Governadores e Capitães Generais fica unicamente cometida a suprema inspeção sobre as Escolas, exceto naqueles casos em que por particulares motivos Eu haja de dispensar neste princípio, e Encarreguei a algum Bispo ou Governador esse especial comissão, e quando assim suceder, aquele Bispo ou Governador a quem Eu confiar esse particular Encargo, será todo o poder para censurar, castigar e vigiar a conduta, exação de serviço e procedimento dos ditos Professores, informando dos que necessitarem maiores castigos, e a total perda da sua Cadeira ficando só autorizado para os suspender do exercício, enquanto se Me dá partes, e o Professor se justifica ou se deixa conhecer a justiça do procedimento que com ele se praticou. Deste modo Confio que se poderá ficar um Plano que seja merecedor da Minha Real Aprovação, e de que se siga a melhor Instrução dos Meus fieis Vassalos nos Meus Domínios Ultramarinos; não devendo esquecer de animar o Estudo das Língua Latina e Grega, para que na Escola daqueles incomparáveis Mestres se forme o gosto da Mocidade instruída; e que segurando-se aos Professores o exato pagamento dos seus Honorários, se aplique também algum fundo para a Jubilação dos Mestres que depois de longos anos de serviço se impossibilitarem e para premiar com algumas Medalhas de valor os Discípulos ou Alunos das mesmas Escolas que anvalmente fizerem alguma composição de distinto merecimento ou publicarem alguma obra que mereça passar a posteridade. $\bigcirc$ que $\mathrm{Me}$ pareceu participar-vos para vossa inteligência e para que da vossa parte coopere para a fiel execução de tudo o que acima fica determinado. Escrita no Palácio de Queluz aos 9 de setembro de 1799. Príncipe Regente.

Nesta mesma conformidade se escreveu ao Arcebispo da Bahia e aos mais Bispos de Pernambuco, São Paulo, Pará, Maranhão, Mariana, Funchal, Angra, Angola, Moçambique, cujo Administrador Episcopal é o Bispo e ao Arcebispo de Goa.

\section{Referências}

DOM JOÃO VI. Príncipe Regente de Portugal. Ordens expedidas para o Brasil sobre as escolas das primeiras letras. Queluz, 1799. Documentos Manuscritos. Notação Doc. 01. Cat. Linhares n 313 . Coleção Linhares da Biblioteca Nacional do Rio de Janeiro, Seção Manuscritos). Disponível em: http://objdigital.bn.br/objdigital2/acervo_digital/div_manuscritos/mss 1457978/mss 1457978.pdf. Acesso em: 3 jun. 2019. 


\section{Documento 06}

\section{Instruções de D. Rodrigo de Souza Coutinho para o Conde de Rezende}

Ilustríssimo e Excelentíssimo Senhor.

$\bigcirc$ Príncipe Regente Nosso Senhor manda remeter a Vossa Excelência a Representação inclusa dos Professores dessa Cidade João Marques Pinto e Manoel lgnácio da Silva Alvarenga em que expõem os motivos da decadência dos Estudos. É Sua Alteza Real servido que Vossa Excelência procure auxiliar e propagar o gosto do Estudo de Latim, Grego e Belas Letras, tendo porém sempre em vista não só que os Professores cumpram com os deveres do seu cargo, mas também que não disseminem máximas perigosas e que os que forem réus de tão enorme crime sejam logo castigados com todo o rigor das Leis depois de um regular e legal Processo. Deus Guarde Vossa Excelência. Mafra, em 4 de outubro de 1799. D. Rodrigo de Souza Coutinho.

\section{Referências}

10 COUTINHO, D. Rodrigo de Souza. Ordens expedidas para o Brasil sobre as escolas das primeiras letras. Mafra, 1799. Documentos Manuscritos. Notação Doc. 01 . Cat. Linhares n’ 313. Coleção Linhares da Biblioteca Nacional do Rio de Janeiro, Seção Manuscritos). Disponível em: http://objdigital.bn.br/obidigital2/acervo_digital/div_manuscritos/ mss 1457978/mss 1457978. pdf. Acesso em: 3 jun. 2019.

\section{Documento 07}

\section{Instruções de D. Rodrigo de Souza Coutinho para o Bispo do Rio de Janeiro}

Excelentíssimo e Reverendíssimo Senhor.

Príncipe Regente Nosso Senhor manda remeter a Vossa Excelência a cópia inclusa de uma Representação dos Professores desta Cidade João Marques Pinto e Manoel Ignácio da Silva Alvarenga em que expõem os motivos da decadência dos Estudos. É Sua Alteza Real servido que Vossa Excelência procure auxiliar e propagar o gosto do Estudo do Latim, Grego e Belas Letras 
tendo porém sempre em vistas não só os que os Professores cumpram com os deveres do seu cargo, mas também que não disseminem máximas perigosas e que os que forem Réus de tão enormes crimes, sejam logo castigados com todo o rigor das Leis depois de um regular e legal Processo. Deus Guarde a Vossa Excelência. Mafra em 4 de outubro de 1799. D. Rodrigo de Souza Coutinho.

\section{Referências}

COUTINHO, D. Rodrigo de Souza. Ordens expedidas para o Brasil sobre as escolas das primeiras letras. Queluz, 1799. Documentos Manuscritos. Notação Doc. O 1. Cat. Linhares n 31 3. Coleção Linhares da Biblioteca Nacional do Rio de Janeiro, Seção Manuscritos). Disponível em: hitp://objigigital.bn.br/obidigital2/acervo_digital/div_manuscritos/ mss 1457978/mss 1457978.pdf. Acesso em: 3 jun. 2019.

\section{Documento 08}

\section{Carta Régia para o Governador de Pernambuco}

Governadores Interinos da Capitania de Pernambuco. Eu, o Príncipe Regente vos Envio muito saudar. Tendo chegado a Minha Real Presença uma carta e informação em que se expõem que o Bispos desta Diocese como Diretor dos Estudos exigira da Junta da Fazenda dessa Capitania o pagamento dos Ordenados de todas as Cadeiras criadas para [...] Capitania, não estavam ainda todas providas [ ] por consequência ficado na sua mão uma grande parte dos referidos Ordenados [ ] da Capitania do Ceará [...]. Hei por bem ordenar-vos que participeis ao dito Bispo: primeiro que dê logo conta do emprego que tem feito do Dinheiro que recebeu pertencente aos Ordenados das Cadeiras vagas; segundo, que cesse de receber a soma pertencente à Capitania do Ceará, que se acha desmembrada e em consequência fora da sua jurisdição nesta parte; terceiro, que não receba mais a Renda das Cadeiras vagas; quarto, que as casas da sua residência só se devem pagar quem mais residir nessas; quinto e finalmente, que a sua conduta a este respeito não tem merecido a Minha Real Aprovação; o que cumprirei dando-lhe parte pela Secretaria de Estado dos Negócios das Marinha e Domínios Ultramarinos 
de assim o haverdes executar. Palácio de Queluz em 18 de julho de 1800. Príncipe. Arcebispo de Goa.

\section{Referências}

DOM JOÃO VI. Príncipe Regente de Portugal. Ordens expedidas para o Brasil sobre as escolas das primeiras letras. Queluz, 1800. Documentos Manuscritos. (Notação Doc. 01. Cat. Linhares no 313. Coleção Linhares da Biblioteca Nacional do Rio de Janeiro, Seção Manuscritos). Disponível em: hitp://objdigital.bn.br/objdigital2/acervo_digital/ div_manuscritos/mss 1457978/mss 1457978.pdf. Acesso em: 3 jun. 2019.

Prof. Dr. Thiago Alves Dias

Pesquisador Visitante da Biblioteca Nacional do Rio de Janeiro

Pesquisador do Laboratório de Experimentação em História Social da Universidade Federal do Rio Grande do Norte

ORCID ID: https://orcid.org/0000-0003-4308-418X

E-mail: dias.thiagoa@gmail.com

Recebido 3 jun. 2019

Aceito 3 out. 2019 